\title{
Erratum
}

\section{Secular trends in desired weight of adults}

\author{
LM Maynard, MK Serdula, DA Galuska, C Gillespie and AH Mokdad
}

International Journal of Obesity (2006) 30, 1461. doi:10.1038/sj.ijo.0803445

Correction to: International Journal of Obesity (2006) 30, 1375-1381. doi:10.1038/sj.ijo.0803297

An error has occurred on page five, in the first paragraph of the second column. The correct sentence is shown below:

Because initial weight losses of $10 \%$ of body weight are recommended of overweight individuals having two or more risk factors, ${ }^{31}$ adults meeting this criterion could achieve or draw near their desired weight by embarking upon a welldesigned weight loss program.

The typesetters would like to apologise for this error. 